\title{
APHIDIDAE (HEMIPTERA) DE ROSA SP, PROCEDENTES DE LIMA-PERÚ
}

\author{
Sandra León-López ${ }^{1}$ \\ Menandro S. Ortiz ${ }^{2}$
}

\section{RESUMEN}

Se reportan las siguientes especies colectadas sobre ejemplares de Rosa sp provenientes de la Provincia de Lima: Macrosiphum rosae (Linnaeus), Myzus persicae (Sulzer), Rhodobium porosum y Wahlgreniella nervata (Gillette). En ésta oportunidad no se encontró a Myzaphis rosarum (Kaltenbach), comúnmente conocida como el áfido menor de las rosas.

Palabras claves: Hemiptera, Aphididae, áfidos, pulgones.

\section{SUMMARY}

In the present paper are recorded the following species collected in Rosa sp of city of Lima: Macrosiphum rosae (Linnaeus), Myzus persicae (Sulzer), Rhodobium porosum y Wahlgreniella nervata (Gillette). In this opportunity not found Myzaphis rosarum (Kaltenbach) common called as lesser rose aphid.

Key words: Hemiptera, Aphididae, aphids.

\section{INTRODUCCIÓN}

Las áreas verdes están por lo general expuestas a una serie de daños, sean estos de tipo fitopatológico o entomológico, los que en ocasiones

1 Alumna de la Facultad de Ciencias Biológicas. Universidad Ricardo Palma. Av. Benavides 5440. Surco-Perú. e-mail: león.lopez.sandra@hotmail.com

2 Facultad de Medicina Humana y Facultad de Ciencias Biológicas. Universidad Ricardo Palma. Av. Benavides 5440. Surco-Perú. e-mail: mortiz@urp.edu.pe 
interactúan creando situaciones complejas. Tal es el caso de los áfidos, insectos polimórficos que viven en colonias y consideradas entre las más importantes plagas de plantas cultivadas.

Frente a un problema de ésta naturaleza, usualmente se recurre a los insecticidas, obteniendo resultados inmediatos, pero a largo tiempo nefastos porque intervienen estos productos alterando a la naturaleza, destruyendo a los enemigos naturales que participan en el control biológico, volviendo a las plagas resistentes o creando efectos de toxicidad tanto a las plantas como a los habitantes.

En medio de ésta situación, surge la alternativa de técnicas que se aprecian dentro del anteriormente citado control biológico de plagas; pero para ello es indispensable que esté apoyado en un conocimiento básico de la biodiversidad, por lo que el presente trabajo contribuye al conocimiento taxonómico de los áfidos provenientes de éstas áreas verdes, en este caso particular sobre ejemplares de Rosa sp sirviendo de base así mismo para un estudio proyectado de sus enemigos naturales.

\section{ANTECEDENTES}

En nuestro país no son muchos los estudios taxonómicos sobre áfidos, predominando más bien los trabajos de entomología agrícola, en donde se aprecia la necesidad de conocer la identidad de las especies de insectos que se hallan en este contexto y de modo particular los áfidos.

Wille (1943) cita por vez primera a los siguientes áfidos Aphis gossypii (Glover), Lypaphis erysimi Kaltenbach (citado como Rhopalosiphum pseudobrassicae), Brevicoryne brassicae (Linnaeus) y Myzus persicae (Sulzer), señalando sus plantas hospederas de interés agrícola, así como sus enemigos naturales.

Beingolea (1961) en el valle de Palpa observa a Aphis citricidus Kirkaldy y Toxoptera aurantii (Boyer de Fonscolombe), atacando los brotes de cítricos. Herrera (1963) cita para el valle de Cañete en el cultivo de papa a Myzus persicae (Sulzer) como especie plaga predominante. Más adelante Beingolea (1967) presenta una relación de enemigos naturales de áfidos que atacan cítricos, mientras que Velarde et al. (1968) establecen la 
existencia de una relación entre estado fisiológico de la planta y grado de infestación por Aphis gossypii (Glover) en algodonero.

Posteriormente, Valencia y Cárdenas (1973) presentan una lista de 19 especies de áfidos que ocurren en 41 especies de plantas en el valle de Ica. Más adelante, Gloria (1978) menciona a Eriosoma lanigerum (Haussmann) como una importante plaga del manzano en Mala (Cañete), mientras que Escalante et al. (1981) presenta una lista de áfidos en frutales (cirolero, manzano, durazno y peral) en Cuzco, señalando los lugares de la planta en los que causan daño.

Entre 1973 y 1998 (Ortiz, 1980, 1998; Ortiz y Rubín de Celis, 1992; Rubín de Celis y Ortiz, 1992; 1994) registran especies importantes de áfidos para diferentes zonas del Perú (Huarochirí, Huaraz, Tingo María, Lambayeque, Huancayo, Valle del Mantaro, Cañete y otras localidades).

\section{MATERIALES Y MÉTODOS}

\section{Zona de Colección}

Lima se encuentra en la costa central del Perú. Forma parte del litoral peruano. El clima en verano la temperatura oscila entre $\operatorname{los} 22^{\circ}$ a $28^{\circ} \mathrm{C}$ y en invierno usualmente no baja de $\operatorname{los} 13^{\circ} \mathrm{C}$. Sin embargo en estas dos estaciones definidas, ambas son húmedas.

Con precisión la ciudad de Lima, se halla ubicada en los $72^{\circ} 02^{\prime} 14^{\prime \prime}$ de longitud oeste y $12^{\circ} 03^{\prime} 02^{\prime \prime}$ latitud sur. Presenta una ligera inclinación de este a oeste. La ONERN (1975) la señala como una formación desértica subtropical, con clima moderado y poca precipitación.

\section{Técnica de Colección}

Los especímenes se colectaron directamente en alcohol $70 \%$ con la ayuda de un pincel suave. Se tomaron datos de lugar, fecha y hospedero. Así mismo fue importante tomar datos sobre la coloración de los especímenes cuando vivos. El hospedero siempre constituyó diferentes ejemplares de Rosa sp. 


\section{Técnica de Montaje}

Los ejemplares fueron montados en láminas de microscopía, siguiendo la técnica recomendada por Hille Ris Lambers (1950).

\section{RESULTADOS}

Se identificaron 4 especies de áfidos. Son las siguientes:

\section{Macrosiphum rosae (Linnaeus)}

Los ejemplares de esta especie son de tamaño mediano a grande, brillantes con colores que van del verde al verde oscuro o del rosado oscuro al rojo marrón o magenta; con cabeza y cornículos de color negro brillante.

Presenta las siguientes características: segmento antenal III con $16-21$ sensorios secundarios, restringidos en la parte basal. Cornículos largos, oscuros, imbricados y distalmente reticulados y ligeramente anchos en la base y estrechándose hacia el extremo distal. Cauda larga y pálida, con 10 a 12 setas. Rostrum no coincide con las coxas medias en las formas aladas y en los ápteros sobrepasa. La parte distal del fémur y extremos de la tibia muy oscuros. El dorso del abdomen de las formas aladas presenta escleritos laterales. Los ápteros a veces con escleritos pequeños.

Sus hospederos, en nuestro medio son especies cultivadas y silvestres de Rosa spp. Ocasionalmente se le encuentra en otras Rosaceae como fresa, frambuesa y Onagranaceae (Epilobium).

En ésta ocasión ha sido colectada sobre rosa cultivada, conformada por colonias relativamente pequeñas localizadas en la parte apical de los tallos, cerca de la cabeza floral y en las hojas más jóvenes. No se halló ejemplares sobre las flores abiertas, pero si en botones florales.

Presenta una distribución mundial y con registros en casi toda Sudamérica. En nuestro país se le reporta en Canta (Rubin de Celis, 1991) y Cañete (León, 1992) como nuevos registros para dichas zonas. 


\section{Myzus persicae (Sulzer)}

Los ejemplares de ésta especie presenta ejemplares que miden de 1,2 a $2,3 \mathrm{~mm}$. Usualmente son de color verde con variada tonalidad. Entre las características de distinción, destaca la convergencia de los márgenes internos de los tubérculos antenales, antenas oscurecidas en las formas aladas, no así en las formas ápteras. Cauda constricta en la parte media y con 6 setas. El aspecto dorsal del abdomen de los alados presenta un área esclerotizada de color oscuro. Los cornículos presentan una longitud que equivale al doble de la longitud de la cauda, además de ser ligeramente ensanchados cerca de la parte distal.

En nuestro medio presenta una gran variedad de plantas hospederas de diversas familias, entre las que se hallan: Chenopodiaceae, Cruciferaceae, Solanaceae, Leguminosae, Compositae, entre otras.

Entre los daños que ocasiona generalmente se halla el enrrollamiento de las hojas jóvenes. Es una especie considerada importante en los que a transmisión de virus fitopatógenos se refiere.

Es cosmopolita, existiendo consecuentemente registros de esta especie en todo el mundo. En nuestro país fue cita por vez primera por Wille (1943) y posteriormente por otros autores, como Herrera (1967), Valencia y Cárdenas (1973), Da Silva et al.(1980), Ortiz (1980), Escalante et al. (1981), en diferentes regiones.

\section{Rhodobium porosum (Sanderson)}

Los individuos alados vivíparos presentan la cabeza y el tórax café amarillo; el abdomen de verde claro a verde amarillento. Los individuos alados vivíparos que se encuentran preservados presentan la cabeza, el tórax, las antenas, excepto la base del segmento III y la mayoría del IV, más claros; $1 / 3$ distal de los fémures, y área distal corta de tibias y tarsos, café intermedio. Los cornículos y escleritos abdominales café claro. La cauda pálida, venas de las alas oscuras; membrana que bordea las venas cubitales, de color café.

Estos individuos tienen de 1,3 a $2 \mathrm{~mm}$ de largo, sus antenas son ligeramente más largas que el cuerpo; processus terminalis de 3,3 a 4,4 veces la base 
del segmento antenal VI; de 14 a 22 sensorios secundarios en el segmento antenal III; de 4 a 11 en el IV; de 0 a 2 en el V. Los cornículos tubulares son ligeramente imbricados, con reborde angosto. La cauda en forma de dedo, y presentan de 5 a 6 setas. Escleritos laterales son pálidos en los segmentos abdominales II-IV, a menudo con un tubérculo pequeño en cada uno

Es conocido como "afido de la rosa amarilla". Rhodobium. porosum probablemente se originó en Norte América (Blackman y Eastop, 1985) pasando posteriormente por muchas zonas (Hille Ris Lambers, 1947) y registrándose tiempo después en el Caribe (Holman, 2009).

En norte América este áfido es holociclico, vive en las hojas y brotes de Rosa spp (especialmente aquellas que son cultivadas) y Fragaria spp (MacGillivray, 1963).

\section{Wahlgreniella nervata (Gillette)}

Las formas ápteras miden de 1,4 a 2,5 mm y son de color verde pálido. Las formas aladas presentan una apariencia similar. Los tubérculos antenales están desarrollados, proyectándose más allá de la parte media del frons. Cauda alargada con 5 setas. Cornículos largos, clavados, pálidos y con ápices oscurecidos.

Coloniza brotes y hojas de rosas cultivadas y silvestres. Poco se conoce acerca de su actividad sobre sus hospederos. Constituye una de las especies que conforman el complejo que se hospedan sobre rosas. En el pasado su distribución estaba restringida al hemisferio norte; sin embargo en Sudamérica existen registros para Brasil (Smith, 1970) y otro para Argentina. Para el primer caso la cita es completa, mientras que para el caso de Argentina, la cita solo se refiere al género Wahlgreniella, encontrada sobre una Cucurbitaceae (Delfino, 1982 en Blackman y Eastop, 1985). En lo que respecta al país esta especie fue registrada por Ortiz et al. (2007) en el valle de Ica, al sur de Lima. 


\section{LITERATURA CITADA}

BEINGOLEA, O. 1961. El valle de Palpa como ejemplo de integrar medidas de control químico y biológico en las plagas de cítricos. Rev. Per. Ent. 2(1): 1-3.

BEINGOLEA, O. 1967. Control Biológico de las plagas de los cítricos en el Perú. Rev. Per. Ent. 10(1): 67-81.

BLACKMAN, R.L.; V.F. Eastop. 1985. Aphids on the World's crops. An Identification Guide. A Wiley Interscience Publication, 466 pp.

DA SILVA, T.H.; M.S. Ortiz; D. Ojeda. 1980. Aphididae (Homoptera) del departamento de Lambayeque. Rev. Per. Ent. 23(1): 121-123.

DELFINO, M.A. 1982 in Blackman, R.L. y V.F.Eastop. 1985. Aphids on the World's crops. An Identification Guide. A Wiley Interscience Publication. 466 pp.

ESCALANTE, J.; M. del Castillo; O. Ochoa. 1981. Plagas de frutales (cirolero, manzano, durazno, peral). Rev. Per. Ent. 24(1): 87-90.

HERRERA, J. 1963. Problemas insectiles del cultivo de la papa en el valle de Cañete. Rev. Per. Ent. 6(1): 1-9.

HILLE RIS LAMBERS, D. 1947. Contributions to a monograph of the Aphididae of Europa. III. Temmimckia 7: 179-319.

HILLE RIS LAMBERS, D. 1950. On mounting aphids and other softskinned insects. Entomol. Ber. 13: 55-58.

HOLMAN, J. (1974) Los áfidos de cuba. Instituto del Libro. La Habana, $304 \mathrm{pp}$.

LEÓN, C.L. 1992. Aphididae (Insecta: Homoptera) provenientes de dos zonas ecológicas de la provincia de Cañete (Lima-Perú). Tesis Lic. Biología. Universidad Ricardo Palma. Facultad de Ciencias Biológicas; 111 pp. 
MACGILLIVRAY, M.E. 1963. The Yellow Rose Aphid, Rhodobium posorum (Sanderson) on strawberry. Can. Ent. 95: 892 - 896.

ORTIZ, M.S. 1980. Aphididae (Homoptera) procedentes de ceja de selva: Tingo María (Huánuco-Perú). Rev.Per.Ent., 23 : 119-120.

ORTIZ, M.S. 1998. Biodiversidad aphidológica (Homoptera: Aphididae) en las áreas cultivadas de la cuenca baja del río Lurin. Biotempo 3: 53-56.

ORTIZ, M.S.; V.E. Rubín de Celis. 1992. Therioaphis trifolii (Monell) (Homoptera: Aphididae, Drepanosiphinae), Nuevo registro para el Perú. Rev. Per. Ent. 35: 51-52.

ORTIZ, M. S., C.E. Escajadillo; V.E. Rubín de Celis (2007) Aphididae (Hemiptera) Procedentes del Valle de Ica-Perú. Biotempo, Vol. 7: 2838.

RUBIN DE CELIS, V.E. 1991. Especies de áfidos hallados en la localidad de Canta, Lima-Perú (Homoptera: Aphididae). Tesis para optar el Grado Académico de Bachiller en Biología. Universidad Ricardo Palma. 114 pp + 24 láminas.

RUBÍN DE CELIS, V.E.; M.S. Ortiz. 1992. Chaitophorus leucomelas Koch (Homoptera: Aphididae, Chaitophorinae) Nuevo registro para Sudamérica. Rev. Per. Ent. 35: 53.

RUBÍN DE CELIS, V.E.; M.S. Ortiz. 1994. Aphididae (Insecta: Homoptera) procedentes de Canta (Lima-Perú). Biotempo 1: 39-4

VALENCIA, L.; N. Cárdenas. 1973. Los áfidos (Homoptera: Aphididae) del valle de Ica, sus plantas hospederas y enemigos naturales. Rev. Per. Ent. 16(1): 6-13.

VELARDE, G; F. Robles; L. Valencia. 1968. Consideraciones sobre el incremento del pulgón de la melaza y el estado de la planta del algodonero. Rev. Per. Ent. 11(1): 109-111. 
WILLE, J.E. 1943. Entomología Agrícola del Perú. Ministerio de Agricultura. Lima-Perú, 520 pp.

WILLE, J.E. 1952. Entomología Agrícola del Perú. Ministerio de Agricultura. Lima-Perú, Segunda edición, 543 pp. 